\title{
Image-based Creep-Fatigue Damage Mechanism Investigation of Alloy 617 at $950^{\circ} \mathrm{C}$
}

\author{
${ }^{1}$ Fraaz Tahir, ${ }^{2}$ Sonam Dahire, ${ }^{3}$ Yongming Liu ${ }^{*}$
}

${ }^{1,2,3}$ School for Engineering of Matter, Transport and Energy, Arizona State University, Tempe AZ 85287, USA 
Abstract: Alloy 617 is a primary candidate material to be used in the next generation of nuclear power plants. Structural materials for these plants are expected to undergo creep and fatigue at temperatures as high as $950^{\circ} \mathrm{C}$. This study uses a hybrid-control creep-fatigue loading profile, as opposed to the traditional strain-controlled loading, to generate creep dominated failure. Qualitative and quantitative image analysis through SEM, EDS, and EBSD, is used to show that hybrid control testing is capable of producing creep dominated failure and that time fraction approach is not a valid indicator of creep or fatigue dominated damage. The focus of image analysis is on surface fatigue cracks and internal creep voids. A creep-fatigue damage interaction diagram based on these micro-scale features is plotted. It is shown that the classical time fraction approach suggested by the ASME code does not agree with the experimental findings and has a poor correlation with observed microscale damage features. A new definition of creep damage fraction based on an effective hold time is found to correlate well with the micro-scale image analysis.

Key words: creep-fatigue; void; imaging; interaction diagram; alloy 617.

*Corresponding Author: Associate Professor, Arizona State University, Mail Code 6106, Tempe, AZ 85287, USA Phone: 480-965-6883Ｅ-mail: yongming.liu@asu.edu 


\section{Introduction}

Creep-fatigue is an important damage mechanism in high-temperature systems that undergo cyclic thermal stresses interspersed with periods of constant load. Examples of such systems include gas turbines, heat exchangers, and microelectronics packaging [1,2]. Recent interest in creep-fatigue interaction in superalloys is driven by the need to evaluate structural materials for future nuclear power plants. The Very High Temperature Reactor (VHTR) is one of six conceptual designs proposed for Generation IV nuclear reactors. The VHTR is a gas-cooled reactor with helium as the primary coolant. The coolant is expected to reach temperatures up to $950^{\circ} \mathrm{C}$ at the reactor outlet, before passing through an Intermediate Heat Exchanger (IHX) which provides process heat for electricity and hydrogen production [3,4]. Steady-state operation of the plant at elevated temperatures leads to creep deformation, whereas loading transients including startup and shutdown generate fatigue $[5,6]$. Hence, creep-fatigue interaction is expected to be a major damage mechanism for structural materials in the IHX. Alloy 617 - a solid-solution strengthened nickel-base superalloy - is the leading candidate material for IHX tubing due to its thermal stability, creep strength, and oxidation resistance at high temperatures [7-9].

Creep-fatigue interaction can be explained microstructurally as a combined effect of creep and fatigue damage, where creep mainly produces internal voids while fatigue generates surface cracks [1]. Alloy 617 contains $\mathrm{M}_{6} \mathrm{C}$ and $\mathrm{M}_{23} \mathrm{C}_{6}$ type carbides, where $\mathrm{Cr}_{23} \mathrm{C}_{6}$ constitutes a large portion of the grain boundary and twin boundary precipitates [10]. These precipitates provide creep resistance by preventing grain boundary sliding, and they also act as void nucleation sites. Under creep-fatigue conditions, multiple voids initiate and coalesce along the grain boundaries and eventually interact with surface cracks to accelerate intergranular crack growth [11]. Alloy 
617 is also known to form a layer of $\mathrm{Cr}_{2} \mathrm{O}_{3}$ on the surface of test specimens in air at elevated temperatures and the thickness of this oxide layer is a function of time and temperature [12]. Underneath the surface oxide layer is a sub-layer consisting mainly of $\mathrm{Al}_{2} \mathrm{O}_{3}$ precipitates [9] and a decarburized region due to the oxidation of chromium carbides [13]. Surface cracks are typically flanked by a $\mathrm{Cr}$ rich oxide layer [7]. Dynamic recrystallization[12] and precipitate redistribution[14] have also been studied for Alloy 617 at temperatures of $800-1000^{\circ} \mathrm{C}$. Studies on microstructural damage induced in Alloy 617 under strain-controlled creep-fatigue loading at $950^{\circ} \mathrm{C}$ observe large amounts of grain-boundary cracking but negligible cavitation, especially for longer hold times $[9,11]$. The absence of creep voids coupled with internal grain boundary cracking [9] indicates that purely strain-controlled loading causes fatigue-dominated failure for Alloy 617 at $950^{\circ} \mathrm{C}$. This can be explained by rapid stress relaxation of Alloy 617 at high temperatures which implies that increasing hold time will not increase the creep damage fraction in the strain-controlled testing [6,7]. This study employs a loading profile with force-controlled hold periods [15] to generate a larger proportion of creep damage, thereby allowing tests to cover the entire range from fatigue dominated to creep dominated failure.

Fatigue life at elevated temperatures is influenced by strain rate, hold time, type of hold stress or strain, and type of loading waveform $[1,16]$. Existing creep-fatigue design curves for Alloy 617 are derived from tests with strain-controlled loading profiles [7,17]. These design curves are based on damage summation rule using the time fraction approach, which is inadequate for life prediction of Alloy 617, regardless of the loading profile ( i.e. straincontrolled or force-controlled hold periods) [6,15]. Moreover, the widely used damage diagram (D-diagram) is a phenomenological representation of macro level testing data. An accurate Ddiagram should be directly supported by the underlying microstructural damage mechanisms, 
which is currently lacking in the open literature. Thus, there is a need for a creep-fatigue life prediction methodology that is informed by an analysis of microstructural damage features. The objective of this study is to qualitatively and quantitatively investigate the microstructural failure mechanisms using imaging analysis. The imaging analysis results are compared with the macrolevel loading parameters, both from classical creep-fatigue damage summation rule suggested by the ASME Boiler and Pressure Vessel Code [17] and a newly proposed approach based on correlational analysis.

The paper is organized as follows. First, the experimental testing procedure for the new testing profile is discussed along with testing matrix, and specimen preparation. Next, qualitative imaging interpretation is given for the damage features observed and their relationship with loading conditions. A quantitative statistical analysis is performed to extract the fatigue crack length distribution and interval void density distribution information. The statistical information is then compared with the classical time fraction approach for life prediction suggested in ASME codes. Following this, the same testing procedure is applied to a set of interrupted test specimens and time-dependent micro-scale damage evolution is investigated. Finally, some conclusions and future work are drawn based on the proposed study.

\section{Experimental testing and imaging analysis}

\subsection{Testing setup and procedure}

Creep-fatigue tests were carried out on a servo-hydraulic load frame equipped with a threezone furnace. Furnace temperature was maintained at $950^{\circ} \mathrm{C}$ for the duration of each test. The test specimens had a circular cross-section, button-head ends, and tangentially blended fillets between the test section and ends, in accordance with ASTM 2714-13. The specimen had a gage 
length of $20 \mathrm{~mm}$ and reduced section diameter of $7.5 \mathrm{~mm}$. The temperature difference along the gage length was maintained below $10^{\circ} \mathrm{C}$ with the aid of four thermocouples wrapped on to the specimen. Strain was measured by an extensometer with ceramic extension rods that remained in contact with the specimen during the test. The experimental testing setup is shown in Fig. 1.

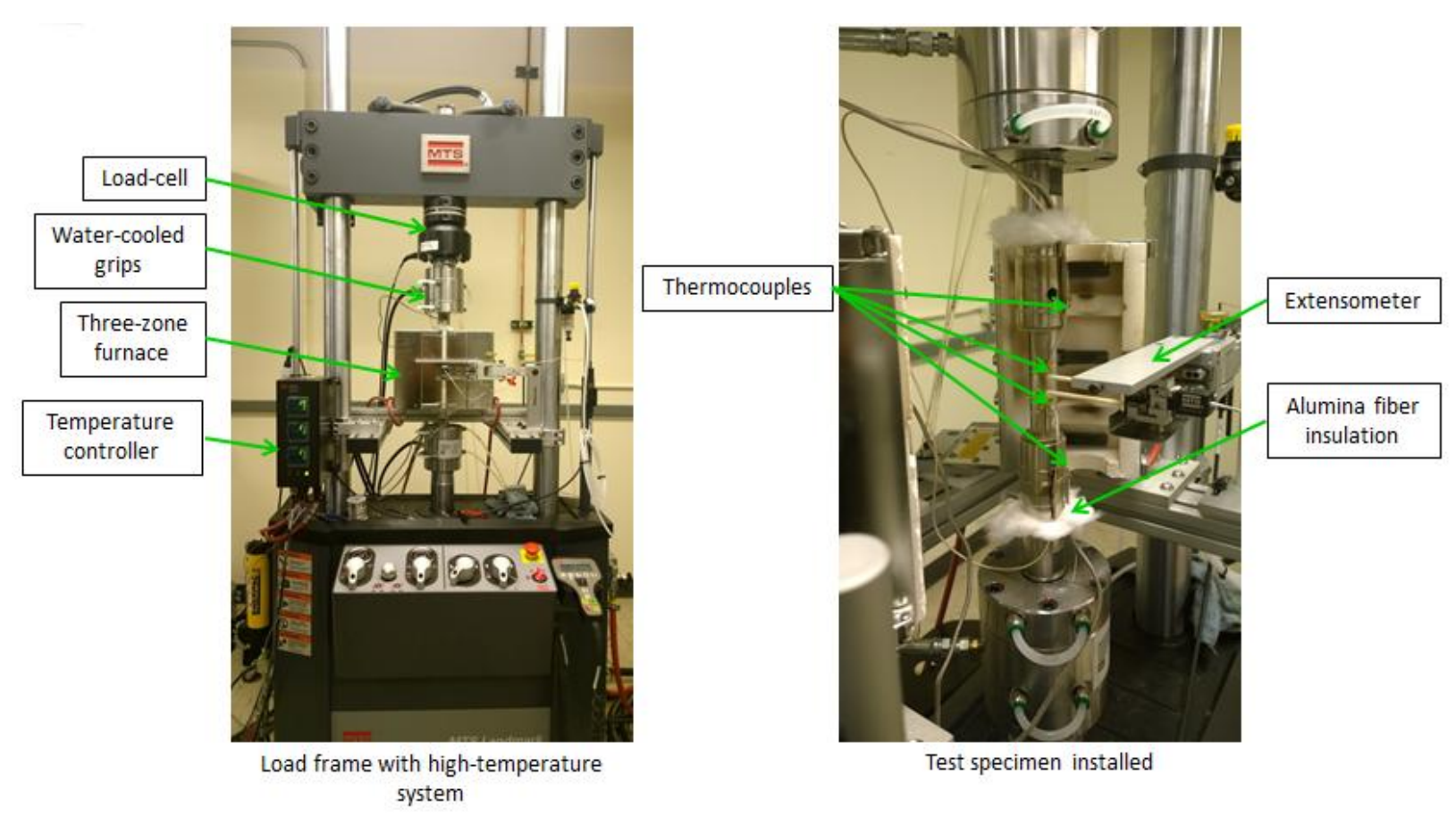

Fig. 1 - Experimental testing setup for creep-fatigue testing of Alloy 617 at $950^{\circ} \mathrm{C}$

The loading profile for the tests was different from the classical strain-controlled stress relaxation testing. Fig. 2 shows the creep-fatigue loading waveform [15] that was used for the tests. The ramps are strain-controlled at a constant rate of $1 \times 10^{-3} / \mathrm{s}$, whereas the hold is forcecontrolled. Combinations of fatigue strain range, holding stress, and hold time were applied to generate varying proportions of creep and fatigue damage. In this study, the testing matrix was designed by varying the fatigue strain range $(0.6 \%$ and $0.8 \%)$, holding stress ( $85 \mathrm{MPa}$ and 100 MPa), and holding time (30 s, $180 \mathrm{~s}$ and $900 \mathrm{~s})$. 

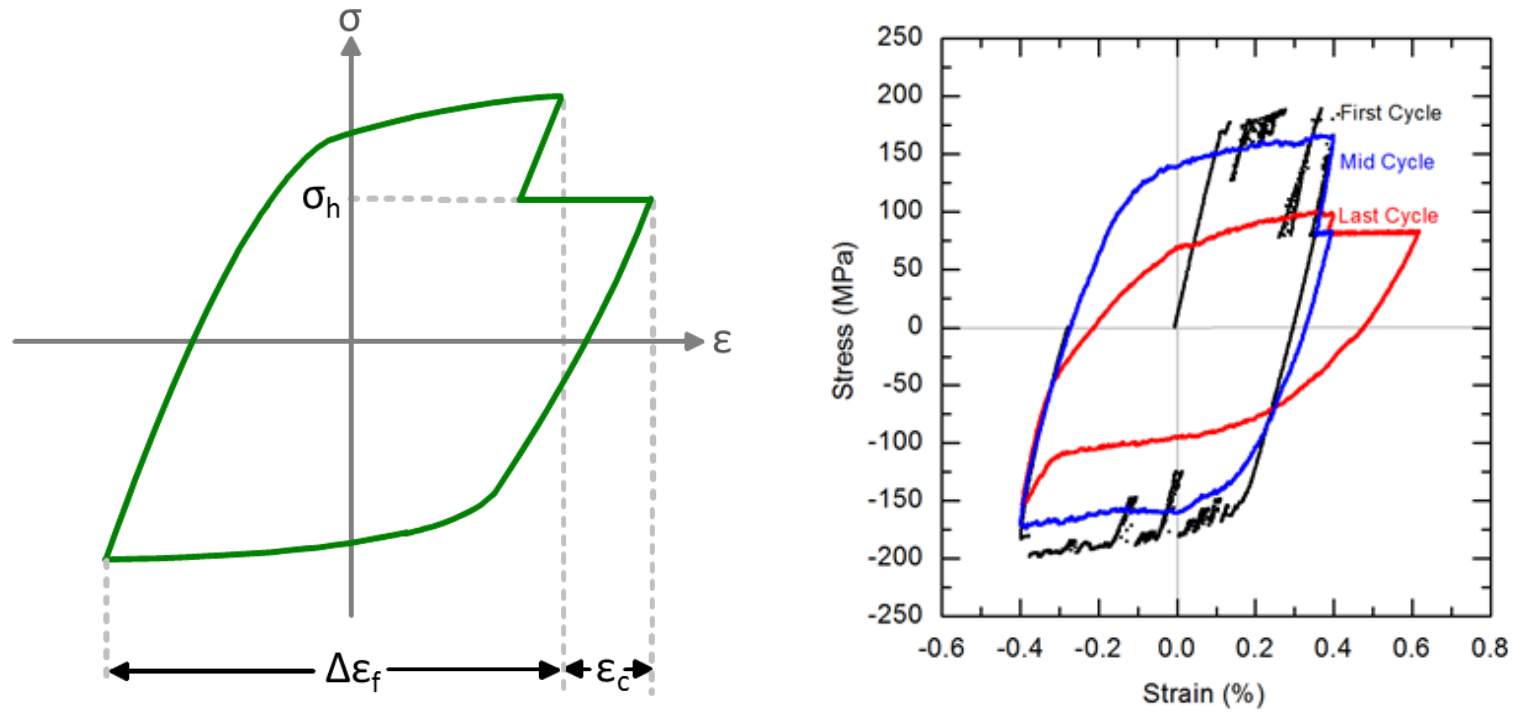

Fig. 2 - (a) A schematic of the loading waveform; (b) Loading waveform for first, mid and last cycle for a test with $0.8 \%$ fatigue strain range and a 10 s hold at $85 \mathrm{MPa}$;

Ruptured test specimens were split in half along the longitudinal axis using Electric Discharge Machining (EDM). The flat side of the sectioned specimens was initially ground with silicon carbide grit papers ranging from 240 to 1200 grit and subsequently polished with 1 micron polycrystalline diamond suspension on a polishing pad. The specimens were then examined under Scanning Electron Microscope (SEM) to obtain qualitative and quantitative information about creep-fatigue damage.

\subsection{Qualitative image analysis for mechanism investigation}

Qualitative image analysis of failure patterns, microstructural damage features, grain structures, and elemental analysis were performed. The failure surfaces were investigated first. There are generally two distinct failure patterns observed in the test specimens. One pattern is associated with significant necking and cup-shape failure surface. The failure surface is very 
rough indicating ductile rupture. This failure pattern usually occurs with longer hold time and lower fatigue cycles. Another pattern is associated with less necking and relatively flat failure surface. The fracture surface is relatively smooth and shows classical failure characteristics of brittle fatigue fracture. This failure pattern usually occurs with shorter hold time and higher fatigue cycles. Fig. 3 shows tests specimens with the abovementioned failure patterns. This observation strongly suggests that there are at least two failure modes in this testing: one is creep rupture-dominated and the other is fatigue fracture-dominated.

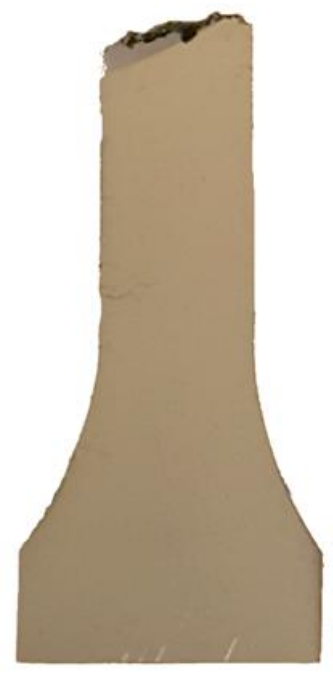

(a)

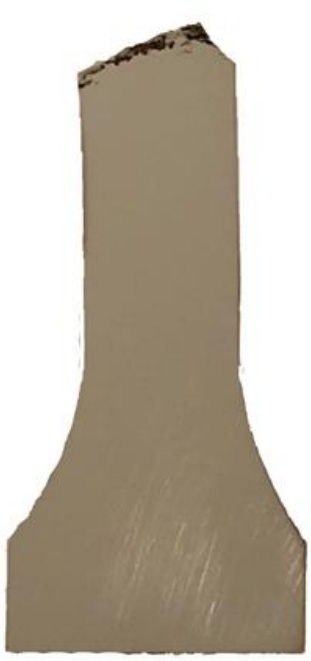

(b)

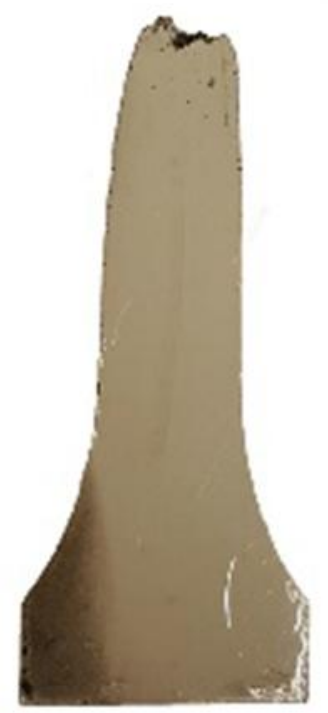

(c)

Fig. 3 - Optical images of the sectioned test specimens for $0.8 \%$ fatigue strain range and $85 \mathrm{MPa}$ holding stress with (a) $30 \mathrm{~s}$ holding time; (b) $180 \mathrm{~s}$ holding time; (c) $900 \mathrm{~s}$ holding time.

Following this, the SEM images for all failure specimens are taken and observations focused on the internal voids and surface cracks. The representative results are shown below with respect to different holding time. Fig. 4 shows the $900 \mathrm{~s}$ hold time test resulted in creep dominated failure as evidenced by large voids which showed signs of coalescence. Surface 
cracks are shorter and tend to link with the sub-surface voids (Figs. 4(a) and 4(b)). Many internal voids are initiated and are linked together to eventually break the specimen. Fig. 5 shows the 180 s hold time test which also produced both voids and cracks, but there was minimal interaction between them. The average crack length is longer than that observed for $900 \mathrm{~s}$ hold and the average void density is smaller than that observed in $900 \mathrm{~s}$ hold (quantitative statistical analysis will be shown later). Fig. 6 shows the 30s hold time test, which resulted in fatigue dominated failure indicated by the long surface cracks, some internal cracks and no voids (or the voids are smaller than the current resolution allows i.e. diameter $>1 \sim 2 \mu \mathrm{m})$. The long surface cracks appear to show a mix of inter-granular and trans-granular crack growth. In general, the surface cracks become more straight and perpendicular to the applied loading direction in $900 \mathrm{~s}$ hold test than that in the $30 \mathrm{~s}$ hold test (see Figs. 4-6). This observation suggests that the fatigue crack propagation tends to be more trans-granular when the holding time decreased. This can be explained by the weakening of grain boundaries by the creep voids. As most internal voids lie on the grain boundaries, significant creep damage will make the fatigue crack propagate along the weakened grain boundaries. If the grain boundary is not weakened significantly (i.e., lower hold time and creep damage), the fatigue crack will propagate as trans-granular cracks.

The crack surfaces were oxidized (see Fig. 6(c) and 6(d)) which is due to the long exposure time of fatigue crack surfaces under high temperature conditions. EDS results will be shown later to confirm the oxidization by elemental analysis. Grain boundary cracks in the interior of the specimen were only observed in fatigue dominated case and it is known that strain-controlled creep-fatigue testing on Alloy 617 at $950^{\circ} \mathrm{C}$ tends to generate interior grain boundary cracks instead of large voids [9]. This implies that most strain-controlled creep-fatigue tests lie in the fatigue dominated failure regime. 

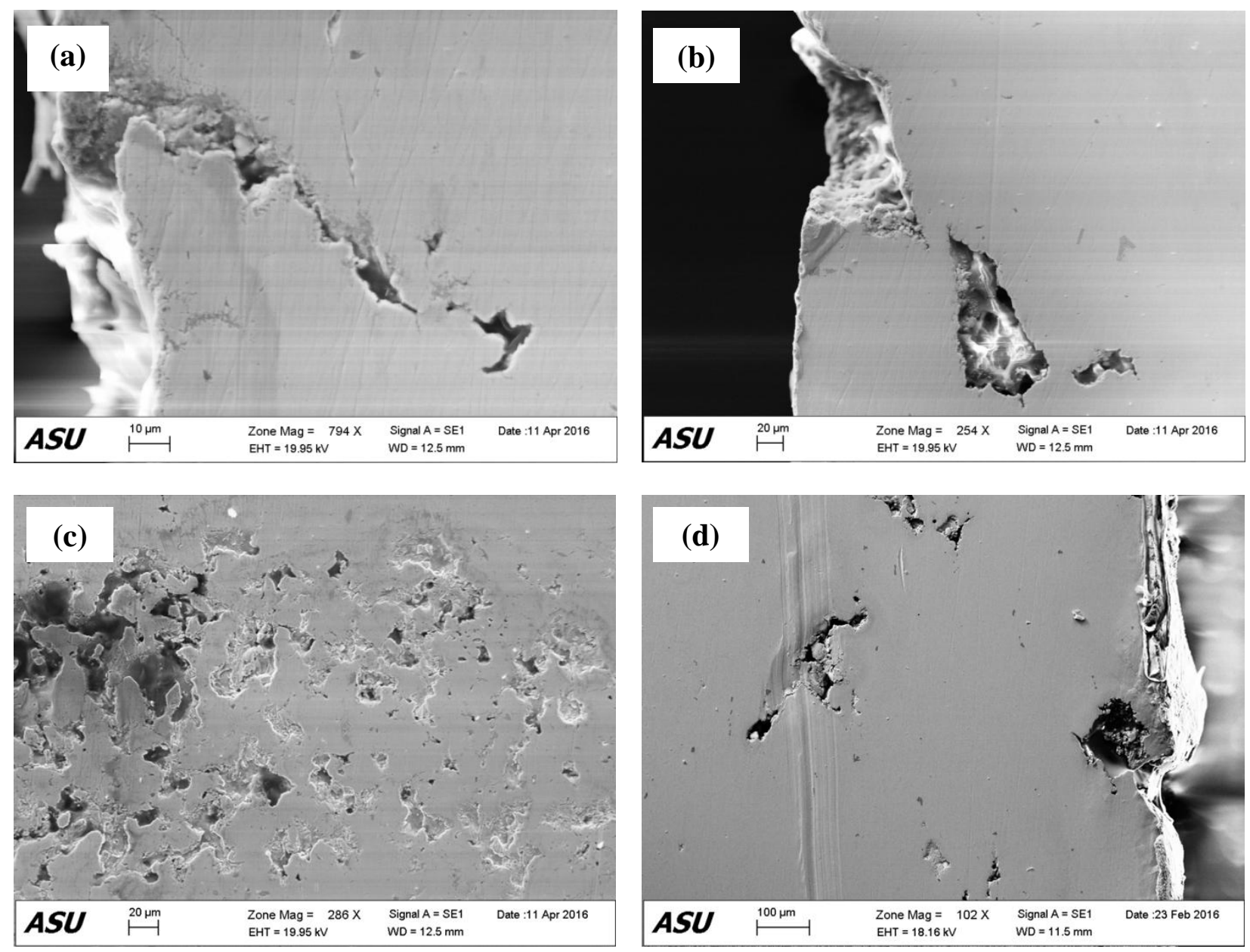

Fig. 4 - Test specimen with creep dominated failure (i.e. $900 \mathrm{~s}$ hold) shows (a), (b) linkage of surface cracks with sub-surface voids; (c), (d) extensive void coalescence near fracture surface.
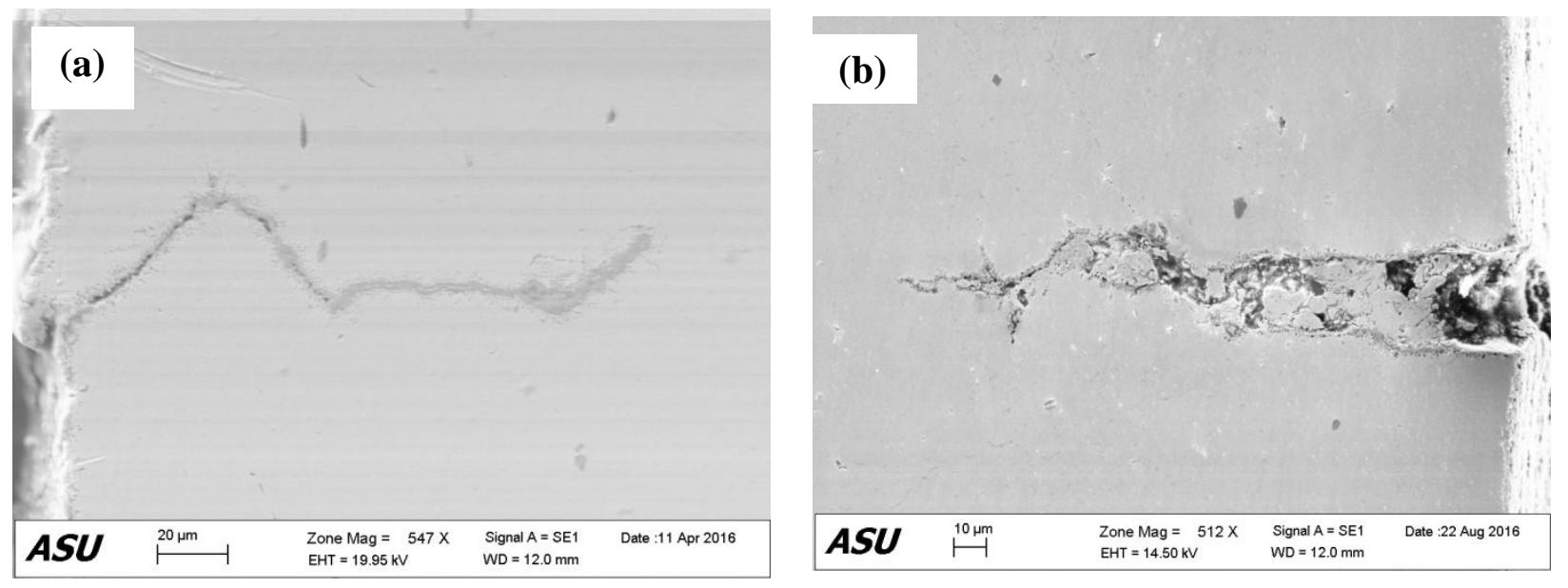

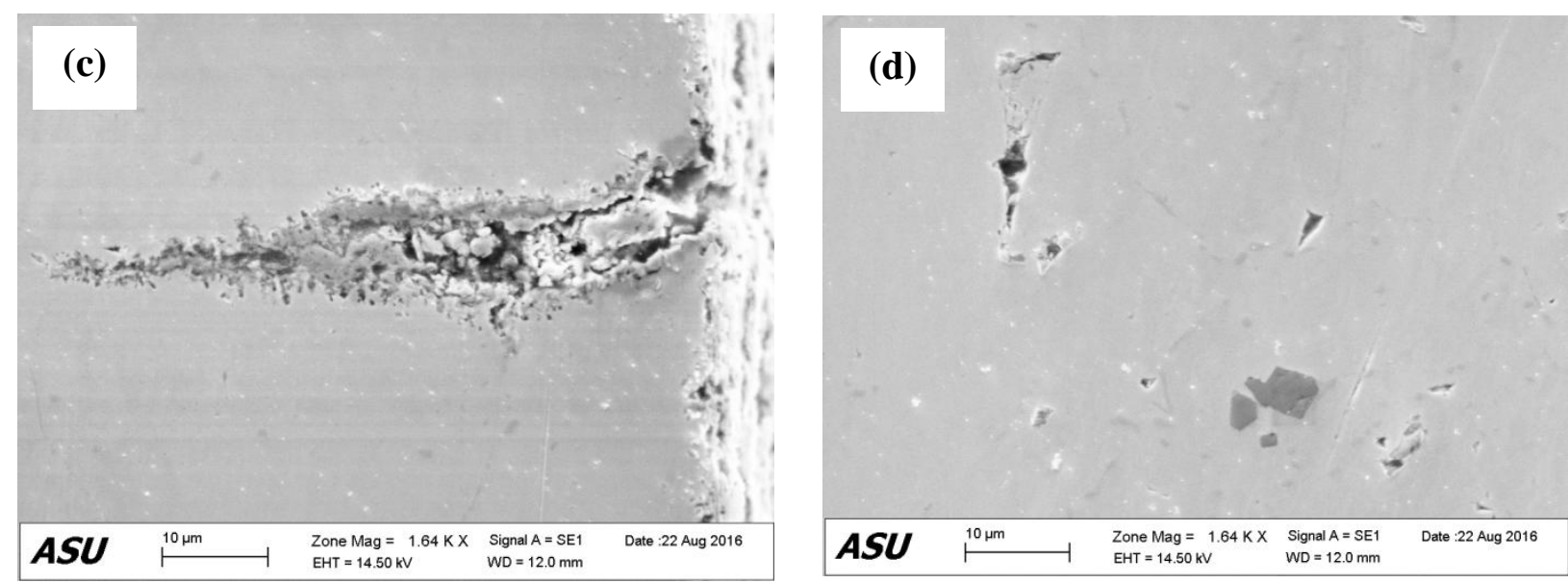

Fig. 5 - Test specimen with creep-fatigue interaction failure (i.e. $180 \mathrm{~s}$ hold) shows (a) mixed inter- and transgranular crack growth (b), (c) transgranular cracks and (d) voids concentrated near the specimen surface.
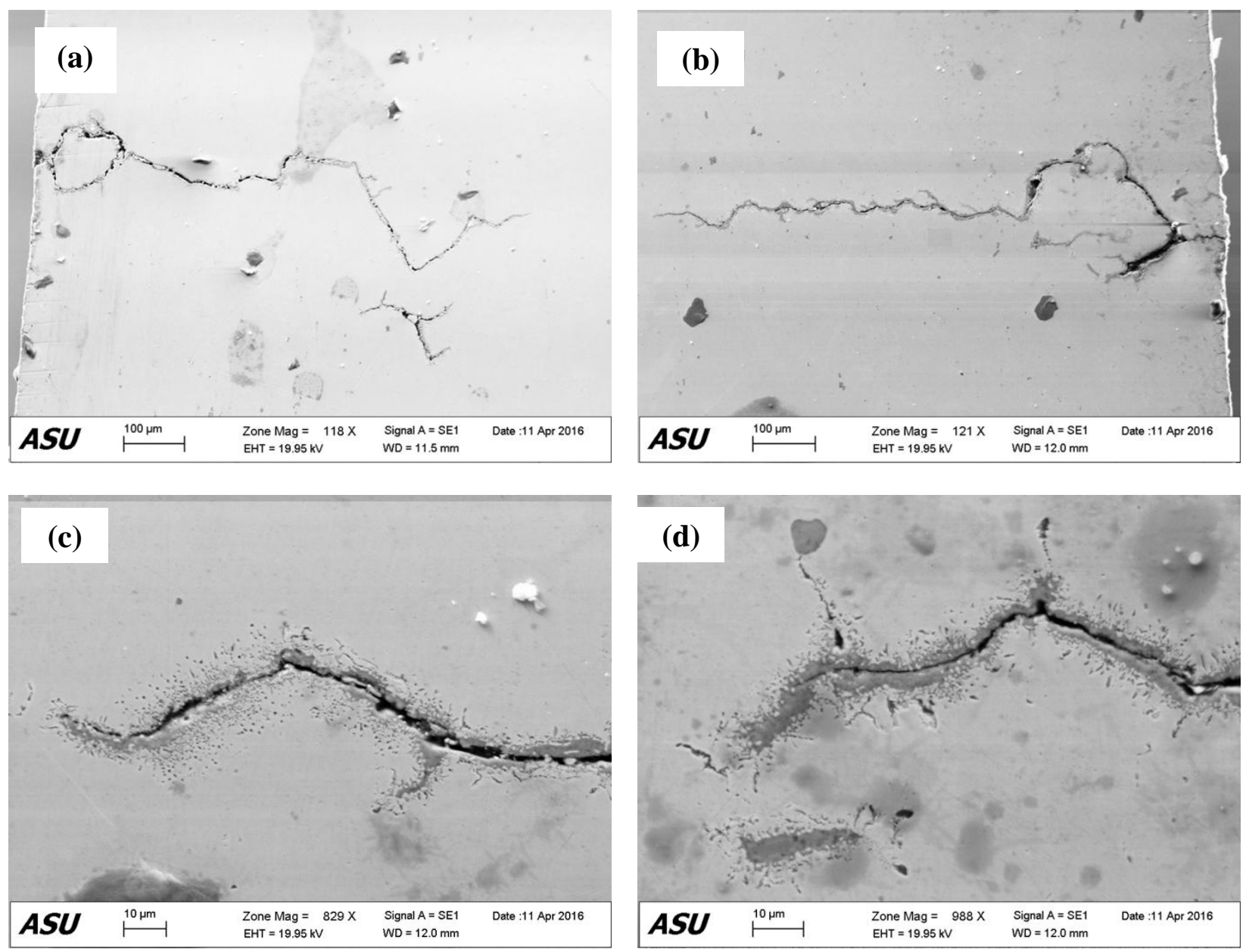

Fig. 6 - Test specimen with fatigue dominated failure (i.e. $30 \mathrm{~s}$ hold) shows (a), (b) long intergranular cracks; (c), (d) thin oxide layer flanking the cracks and grain boundaries ahead of the crack tip. 
Next, Electron Backscatter Diffraction (EBSD) was used on a specimen with creep dominated failure to identify the grain structure with respect to damage. It is observed that most internal voids are on the grain boundaries. An example is shown in Fig. 7. SEM images were obtained to identify the region of interest (ROI) with voids. The EBSD images for the ROI were then compared / overlapped with the SEM images. It is clear that the voids were generated at the grain boundaries (GB), especially near triple junctions and GBs with high misorientation angles. The voids tend to grow along the GB and link with the neighboring GB voids.

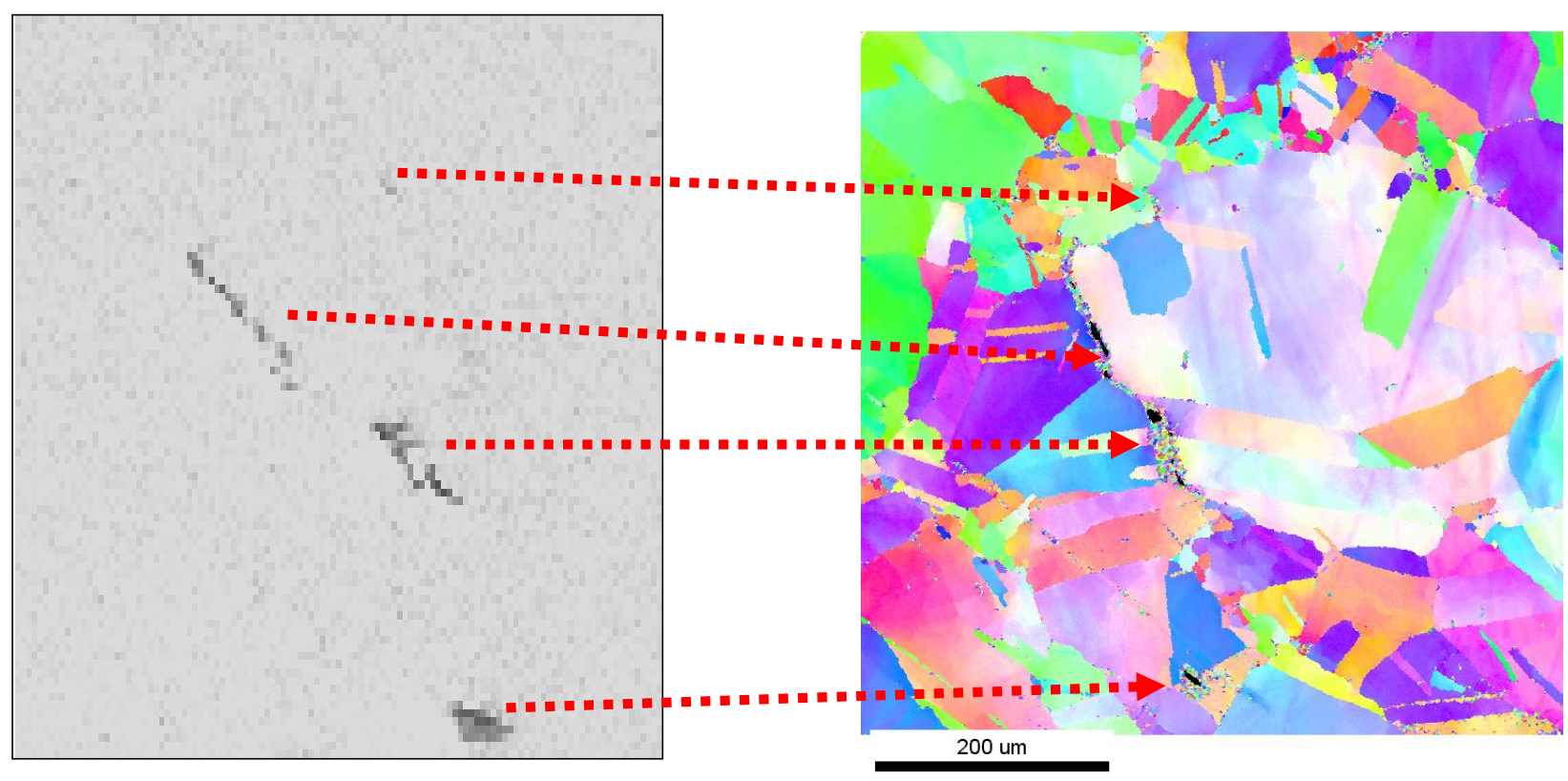

Fig. 7 - EBSD and SEM imaging for internal voids of failed specimen

Following this, Energy Dispersive Spectroscopy (EDS) was used to identify the elements near the fatigue cracks. Fig. 8 show an EDS phase map for a test specimen with $0.6 \%$ fatigue strain range, $100 \mathrm{MPa}$ holding stress, and $30 \mathrm{~s}$ hold time. This condition represents fatigue dominated failure for current loading profile. The crack surfaces were flanked by an external layer of chromium oxide and an internal layer of aluminum oxide. The precipitates were titanium nitride. In contrast to the fatigue dominated test specimen, the creep dominated specimen showed 
blunt cracks with no oxidation layer. This indicates that creep dominated specimens developed surface cracks near the end of the cycle life, whereas fatigue dominated specimens developed surface cracks early on, allowing sufficient time for the exposed surfaces to oxidize. The EDS composition map is shown in Fig. 8.

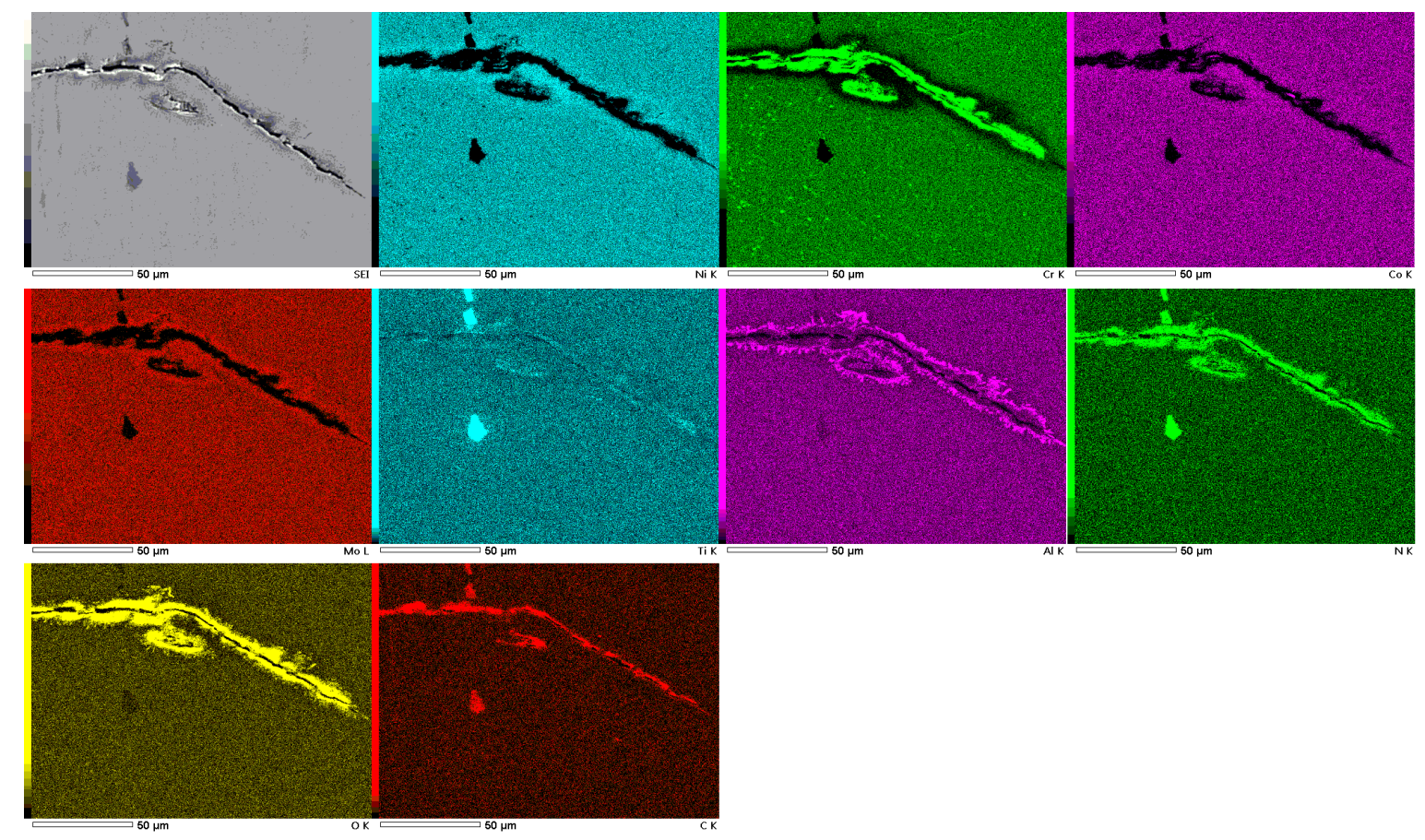

Fig. 8 - EDS phase maps for surface crack on a test specimen with fatigue dominated failure

Fig. 9 compares the relation between cycle life and hold time for hybrid-control and strain control tests. In traditional strain-controlled creep-fatigue tests, increasing the hold time does not lead to increase in creep damage, due to rapid stress relaxation of Alloy 617, as shown in Fig. 9(b). However, hybrid-control tests show a reduction in cycle life with increase in hold time, as shown in Fig. 9(a). Generating creep dominated damage is one of the main advantages of using a hybrid-control loading profile. Micro-scale image analysis provides physical evidence for this behavior. Specimens undergoing hybrid-control loading show that longer hold time does 
leads to more creep damage as characterized by void initiation and coalescence at grain boundaries whereas shorter hold time leads to fatigue dominated damage as represented by oxidation-assisted crack growth at exposed outer surfaces.

(a)

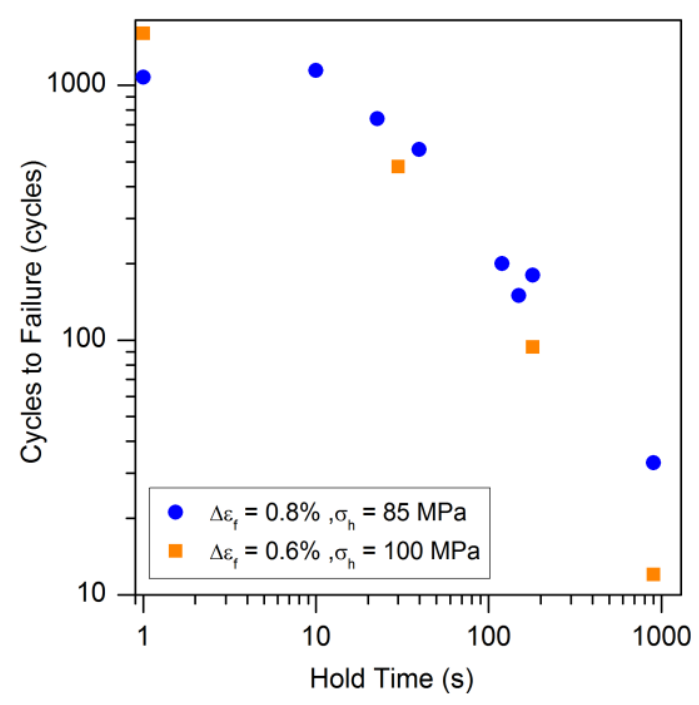

(b)

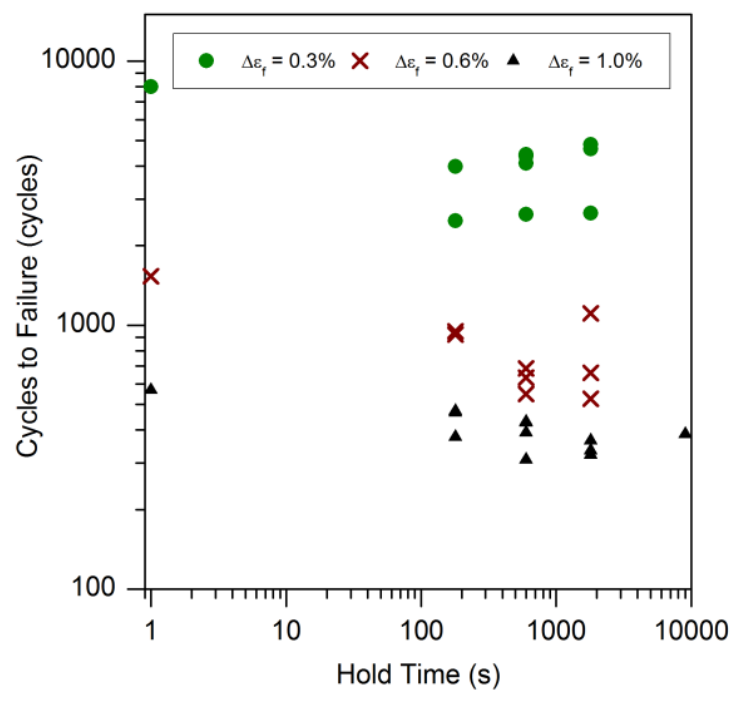

Fig. 9 - Relation between cycle life and hold time for (a) hybrid-control tests; (b) strain-control tests[18].

\subsection{Digital imaging measurements and statistical data analysis}

Above discussion was interpretation of imaging for experimental observations of a new testing profile that is capable of producing creep dominated failure. It provides insights into the damage mechanisms involved, but does not provide quantitative measurements for future life prediction models and design curves. Thus, this section focuses on digital imaging measurements and statistical data analysis to achieve this goal. The focus is on the following metrics: surface crack length, number of voids, and void area / area fraction.

The new hybrid-control creep-fatigue tests covering a range of creep and fatigue fractions were used for image-based damage analysis in SEM. The length of each surface crack along the 
gage length of the specimen was measured in SEM to provide an estimate of fatigue damage. Fig. 10 shows the tail of an empirical cumulative distribution function of the crack lengths from three tests with a fatigue strain range of $0.6 \%$, a holding stress of $100 \mathrm{MPa}$ and hold times of 30, 180, and 900s, respectively. The distribution of crack lengths less than $200 \mu \mathrm{m}$ was almost identical for the three tests. However, the $10 \%$ percentile curves for cracks with lengths greater than $200 \mu \mathrm{m}$ showed significant differences between creep dominated and fatigue dominated failure modes. In this case, 30s hold time represents fatigue dominated failure whereas a 900s hold time represents a creep dominated failure. The fatigue dominated case has much longer crack lengths compared to the creep dominated case. It should be noted that the mean crack length is not compared here as the failure is an extreme event and only the tail region (i.e., longest cracks in the specimen) affect the final failure. In the current investigation, the longest crack observed in the fatigue dominated specimen is about 10 times the length of the longest crack in the creep dominated case. The mean and standard deviation of the measured cracks are shown in Table. 1. It is observed that, not only the mean crack length, but also the standard deviation of the crack length increases as the hold time decreases. 


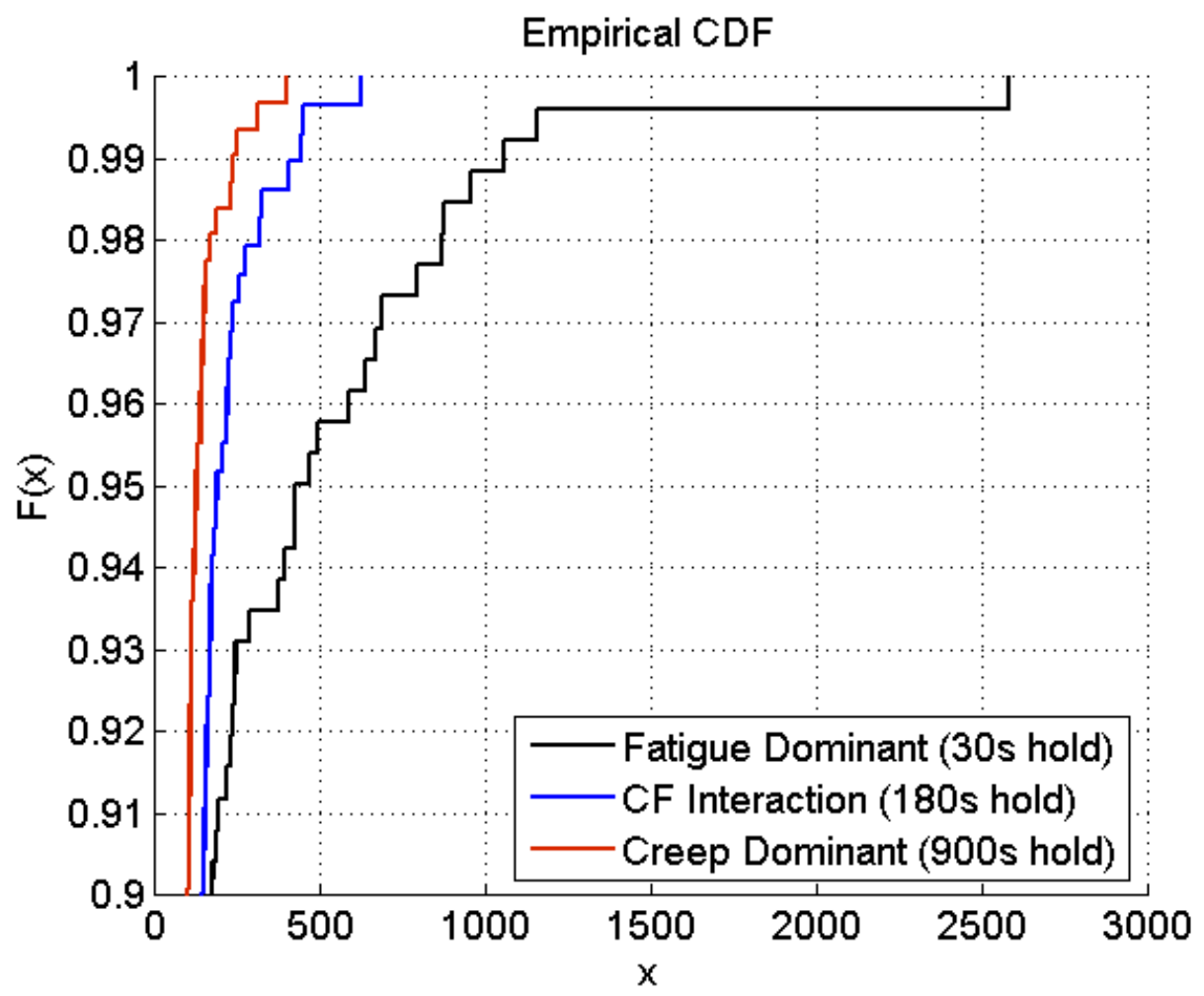

Fig. 10 - Empirical cumulative distribution function $(\mathrm{F}(\mathrm{x}))$ for length of surface cracks (x) during creep-fatigue tests with varying hold time

\begin{tabular}{|c|c|c|}
\hline $\begin{array}{c}\text { Hold Time, } \\
\mathbf{S}\end{array}$ & $\begin{array}{c}\text { Mean Crack } \\
\text { Length } \\
(\boldsymbol{\mu m})\end{array}$ & $\begin{array}{c}\text { Standard } \\
\text { Deviation } \\
(\boldsymbol{\mu m})\end{array}$ \\
\hline $\mathbf{3 0}$ & 94.05 & 230.62 \\
\hline $\mathbf{1 8 0}$ & 69.06 & 76.30 \\
\hline $\mathbf{9 0 0}$ & 51.59 & 47.80 \\
\hline
\end{tabular}

Table. 1 - Mean crack length and standard deviation corresponding to different hold times 
The next digital measurements were for the internal voids. Multiple SEM images were captured across the width of the specimen at distances of $1 \mathrm{~mm}, 3 \mathrm{~mm}$ and $5 \mathrm{~mm}$ from the rupture surface, as shown in Fig. 11. The reason is that the internal void distribution is not uniform across the length of the specimen. Image analysis was performed to determine the ratio of area covered by voids to the total area in the image. This void area fraction was used as an indicator of creep damage in the sample. Fig. 11 summarizes the void damage in a test specimen with creep dominated failure i.e. $0.6 \%$ fatigue strain range, $100 \mathrm{MPa}$ holding stress, and $900 \mathrm{~s}$ hold time. The results of image analysis for this particular sample are shown in Table 2 . The area fraction of voids and average void size was highest near the rupture surface but the number of voids was lowest, indicating that final failure was caused by void coalescence. Only voids larger than $1 \mu \mathrm{m}$ were analyzed. A similar analysis was performed on the fatigue dominated test specimen with $30 \mathrm{~s}$ hold time and creep-fatigue interaction test specimen with 180 s hold time. No voids larger than $1 \mu \mathrm{m}$ were detected on the fatigue dominated test specimen with $30 \mathrm{~s}$ hold time. For the creep-fatigue interaction specimen, voids were present but their average size and area fraction was less than the creep dominated specimen. 


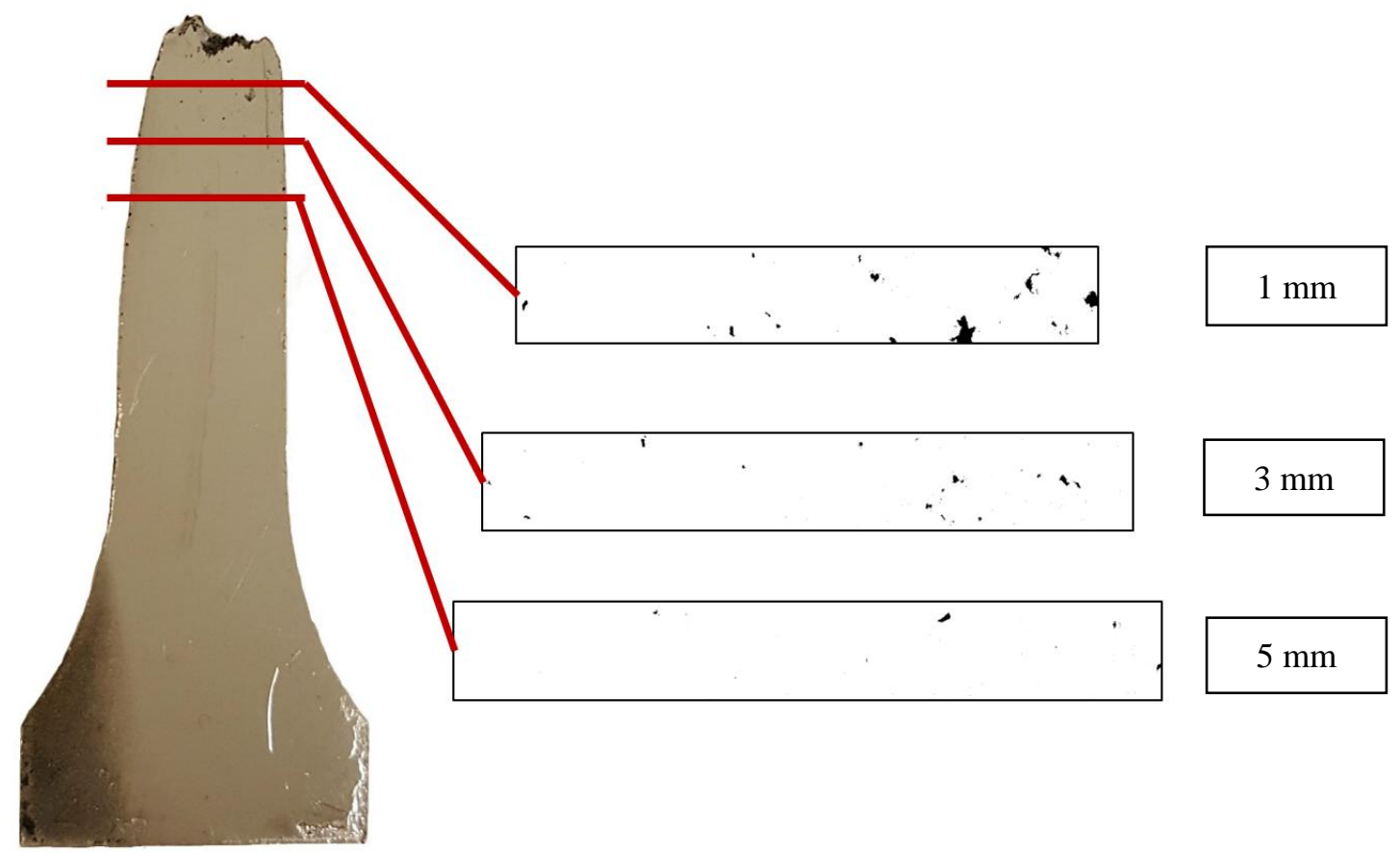

Fig. 11 - Analysis of voids on a sectioned half of the ruptured test specimen

\begin{tabular}{c|c|c|c}
$\begin{array}{c}\text { Distance from } \\
\text { Fracture } \\
\text { Surface, } \\
\mathbf{m m}\end{array}$ & $\begin{array}{c}\text { No. of } \\
\text { Voids }\end{array}$ & $\begin{array}{c}\text { Average Void } \\
\text { Size, } \\
\boldsymbol{\mu \mathbf { m } ^ { 2 }}\end{array}$ & $\begin{array}{c}\text { Area Fraction } \\
\text { of Voids, \% }\end{array}$ \\
\hline $1 \mathrm{~mm}$ & 56 & 1135.88 & 1.492 \\
\hline $3 \mathrm{~mm}$ & 86 & 206.96 & 0.373 \\
\hline $5 \mathrm{~mm}$ & 100 & 104.24 & 0.207 \\
\hline
\end{tabular}

Table. 2 - Variation in number, size and area fraction for voids at fixed distances from the rupture surface

\section{Correlational analysis for imaging measurement and mechanical damage parameters}

As mentioned in the introduction, one benefit for the rigorous quantitative imaging analysis is that it can provide a statistical correlation with the external damage parameters. Thus, the 
micro-scale damage features and macro-level damage parameters can be linked. This section focuses on this objective. For the micro-scale damage features, the crack length and void area fraction are selected. For the macro-level damage model, the widely used ASME damage summation rule with time fraction approach is applied. The damage parameters are fatigue fraction (i.e., number of cycles to failure in creep-fatigue testing normalized by the corresponding pure fatigue failure cycles) and creep fraction (summation of hold time normalized by the creep rupture time). It is expected that, if the model is correct, a correlation between the micro-scale features and damage parameters can be identified. The following analyses are done for fatigue and creep correlation, respectively.

If fatigue damage is considered as initiation and propagation of surface cracks and creep damage is considered as initiation, growth, and linkage of voids, then creep-fatigue interaction diagram based on these damage features can provide useful insights for the purpose of developing microstructure-informed creep-fatigue life prediction models. Tests were performed with varying fatigue strain range, holding stress, hold time, and type of hold to generate creepfatigue interaction. The type of hold refers to whether the force-controlled hold during each cycle was for a fixed time period or up to a fixed strain value. Fig. 12 shows a significant variation in crack lengths across different tests for cracks longer than $200 \mu \mathrm{m}$. Specimens with larger fatigue damage fraction have longer cracks indicating that crack growth is the primary damage mechanism for fatigue dominated failure. This hypothesis is further supported by the linear increase in mean and standard deviation of crack lengths with increasing fatigue damage fraction, as shown in Fig. 13. The fatigue damage fraction was slightly larger than unity for the 10 s hold test. This implies that a 10 s hold time test is similar to a pure fatigue test and that the 10s hold is not enough to induce creep damage. It is interesting to note that the test with force- 
controlled hold up to a fixed strain (green circle in plot) does not show significant variation from the linear trend of mean and standard deviation of crack lengths. This analysis indicates that the fatigue fraction is a good candidate for the development of creep-fatigue models as it closely related to the micro-scale damage (crack length and its variance).

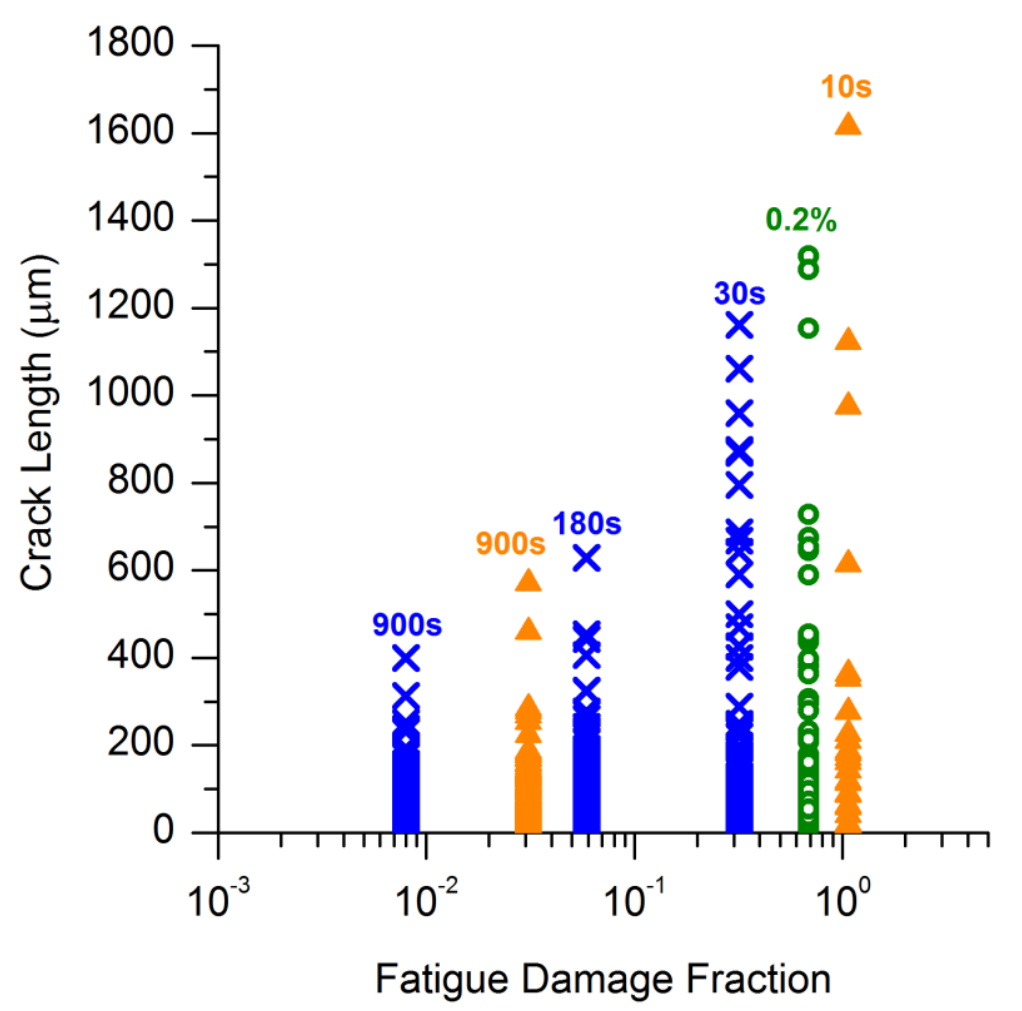

\begin{tabular}{|c|c|c|c|}
\hline & $\begin{array}{c}\text { Fatigue Strain } \\
\text { Range (\%) }\end{array}$ & $\begin{array}{c}\text { Holding } \\
\text { Stress (MPa) }\end{array}$ & Type of Hold \\
\hline $\mathrm{X}$ & 0.6 & 100 & time \\
\hline $\mathbf{\Delta}$ & 0.8 & 85 & time \\
\hline 0 & 0.8 & 85 & strain limit \\
\hline
\end{tabular}

Fig. 12 - Variation in distribution of crack lengths with fatigue damage fraction. Error bars represent standard deviation. 

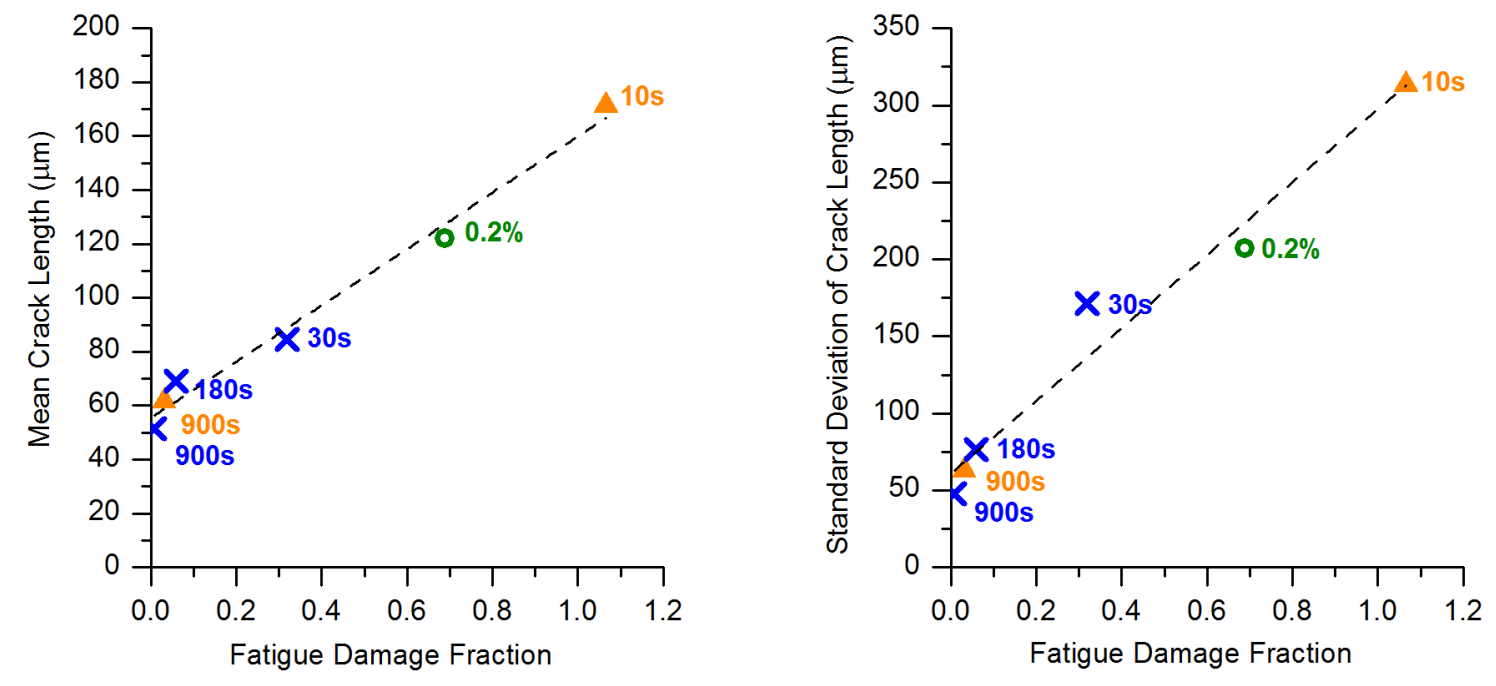

\begin{tabular}{|c|c|c|c|}
\hline & $\begin{array}{c}\text { Fatigue Strain } \\
\text { Range (\%) }\end{array}$ & $\begin{array}{c}\text { Holding } \\
\text { Stress (MPa) }\end{array}$ & Type of Hold \\
\hline $\mathrm{X}$ & 0.6 & 100 & time \\
\hline $\boldsymbol{\Delta}$ & 0.8 & 85 & time \\
\hline $\mathbf{0}$ & 0.8 & 85 & strain limit \\
\hline
\end{tabular}

Fig. 13 - Mean and standard deviation of crack length increase with increasing fatigue damage fraction 


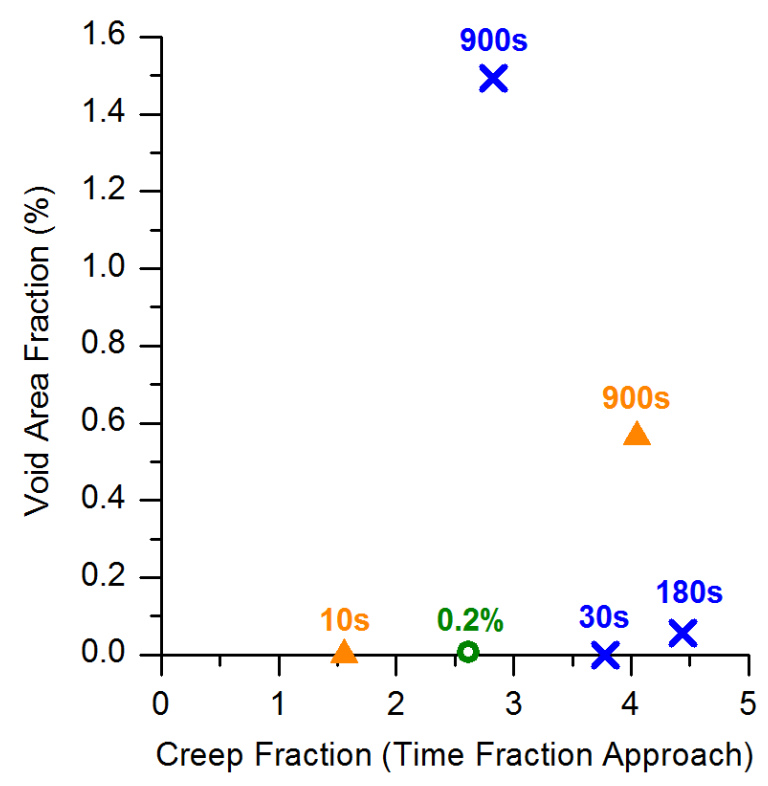

Fig. 14 - Relation between void area fraction $1 \mathrm{~mm}$ below the rupture surface and creep damage fraction using time fraction approach

Next, the correlation is done for the internal void area fraction and creep time fraction. Since the internal voids are not uniformly distributed across the specimen length, the void area fraction was calculated at $1 \mathrm{~mm}$ distance from the rupture surface, as described in the previous section. Fig. 14 illustrates that there is no relation between void area fraction and creep damage fraction calculated using the classical time fraction approach. It is also interesting to note that the $900 \mathrm{~s}$ hold (blue circle) has less "creep damage fraction" compared to the $30 \mathrm{~s}$ and $180 \mathrm{~s}$ hold. This is contrary to expectation and evidence provided by imaging analysis described earlier. This suggests that the widely used time fraction approach for calculation of creep damage is not a good candidate for the creep-fatigue life prediction as it does not correlate well with the damage features; in particular the void area fraction.

Creep-fatigue interaction in steels is traditionally represented by a bilinear trend curve on 
an interaction diagram that is based on linear damage summation rule and time fraction approach[16,19]. Fatigue damage is represented as a cycle fraction and creep damage is represented as time fraction. Although, the time fraction approach is employed in nuclear component design codes, namely, ASME BPVC Section III Subsection NH[17] and RCCMR[20], this approach has several limitations[21,22]. Moreover, elevated temperature strain controlled testing of Alloy 617 fails to produce a clear trend on an interaction diagram due to irregular values of creep damage fraction [5,15]. Further theoretical and experimental study is required to find another parameter that is best correlated with the observed internal voids. The current study only investigates a simple alternative mechanical parameter, called effective creep time fraction. The basic idea is briefly discussed here. For the investigated hybrid control loading profile, the total creep strain will monotonically increase from cycle to cycle due to the softening. Thus, the hold time can be divided into two parts: one part is to recover the creep strain happens in the previous cycle and the other part is to increase the creep strain to a new high level. The second part is referred to as the effective hold time and it indicates the time is "effective" in causing monotonic creep strain increment. The summation of this part of hold time for all cycles can be normalized by the creep rupture time and is defined as the effective creep fraction. Fig. 15 shows that the observed internal void area fraction has a very good correlation with the effective time fraction definition. It also shows that the creep damage fraction increases as the hold time increases unlike the contradictory results from the classical time fraction approach. 


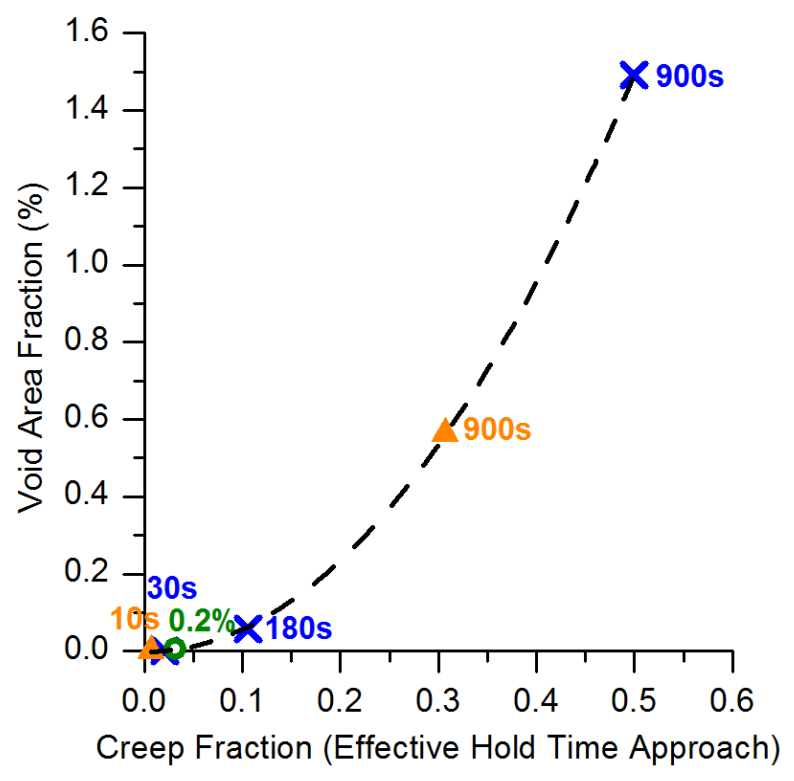

Fig. 15 - Correlation between void area fraction and effective hold time creep fraction

Another way to represent the correlational analysis is shown below using the concept of the $\mathrm{D}$ diagram. In the $\mathrm{D}$ diagram, $\mathrm{x}$-axis represents the fatigue damage and $\mathrm{y}$-axis represents the creep damage. Fig. 16 (a) constructs the "D" diagram using the microstructurally observed crack length and void area fraction. Both mean and 90\% quantile curves are shown. The micro-scale imaging analysis gives a clear bilinear trend, representing the two distinct failure modes, i.e., creep dominated and fatigue dominated. Fig. 16(b) shows that D diagram using the damage parameters: fatigue fraction and the effective creep fraction. The trend is very similar to the micro-scale imaging results as it also shows a clear bilinear trend. Thus, these two parameters may be used for future life prediction model development as a strong correlation with microstructural damage features is obtained. 


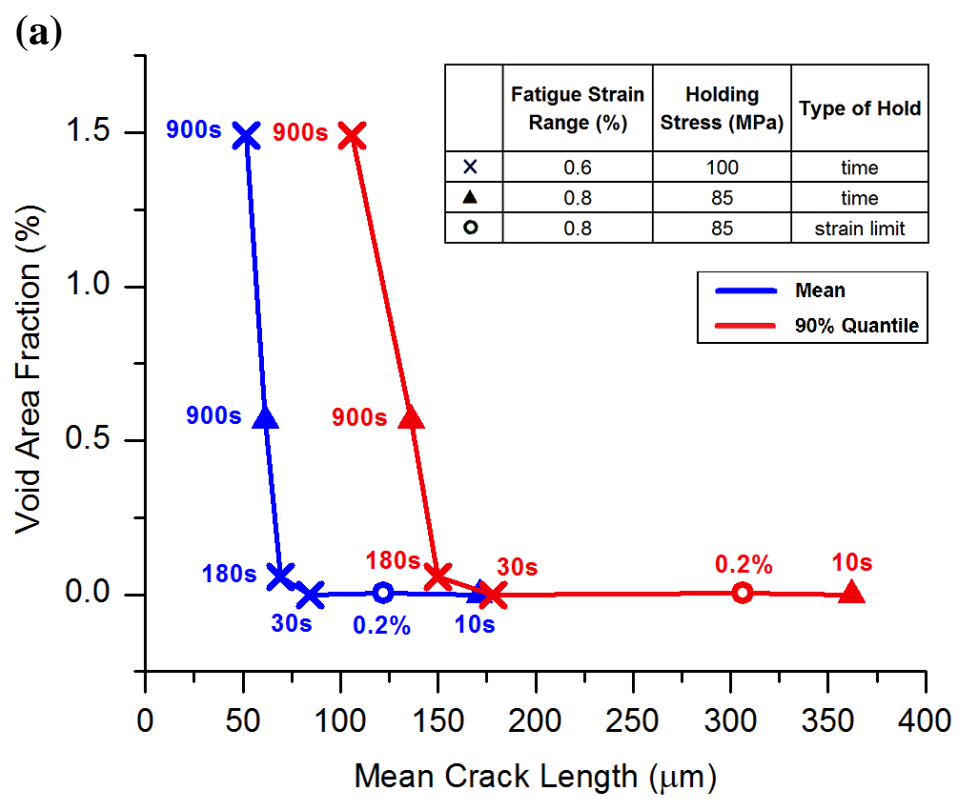

(b)

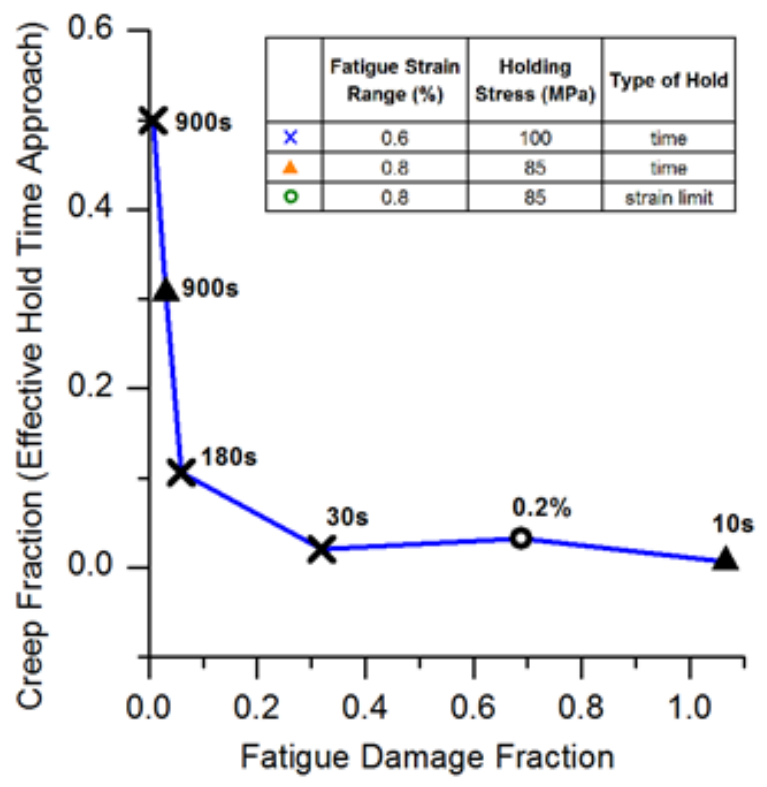

Fig. 16 -D diagram construction using micro-scale imaging results and damage parameters (a) Damage interaction diagram based on microstructure; (b) Damage interaction diagram based on effective hold time approach. 


\section{CONCLUSION}

Hybrid-control testing can generate creep dominated failure. Image-analysis confirms that, unlike the classical strain-controlled testing, the new hybrid control testing profile can increase the creep damage by increasing the hold time under force-control. Qualitative image analysis shows that there are two distinct failure modes in the investigated testing cases: ductile creep dominated failure with long hold time and brittle fatigue dominated failure with short hold time. The fatigue crack length correlates well with the cycle number ratios but the void area fraction does not correlate well with the classical time fraction used by ASME code. An effective hold time approach (i.e. only considering the part of the hold time when net creep strain increase happens) correlates well with the observed void area fraction and provides an alternative way to formulate the damage interaction diagram. These conclusions currently apply to creep-fatigue interaction in Alloy 617 at $950^{\circ} \mathrm{C}$ under force-controlled hold periods. A similar analysis can be performed on tests with strain-controlled hold periods, to confirm their inadequacy for generating significant creep damage. Further work may also include the development of a life prediction model, similar to the effective hold time approach, which mimics the bilinear damage curve obtained through micro-scale image analysis.

\section{ACKNOWLEDGEMENTS}

This work is sponsored by the U.S. Department of Energy (DoE) under the Nuclear Energy University Programs (NEUP) initiative (DE-NE0000675). The authors gratefully acknowledge Richard Wright (INL) and Sam Sham (ANL) for their input and discussions.

\section{REFERENCES}

[1] K.B.S. Rodriguez, P., Rao, Nucleation and Growth of Cracks and Cavities under CreepFatigue Interaction, Prog. Mater. Sci. 37 (1993) 403-480. 
[2] A. Dasgupta, Solder Creep-Fatigue Analysis by an Energy-Partitioning Approach, J. Electron. Packag. 114 (1992) 152-160.

[3] D. Chapin, S. Kiffer, J. Nestell, The Very High Temperature Reactor: A Technical Summary, MPR Assoc. (2004).

[4] J.M. Corum, J.J. Blass, Rules for design of Alloy 617 nuclear components to very high temperatures, Oak Ridge Natl. Lab. (1991).

[5] X. Chen, M.A. Sokolov, S. Sham, D.L. Erdman, J.T. Busby, K. Mo, et al., Experimental and modeling results of creep-fatigue life of Inconel 617 and Haynes 230 at 850C, J. Nucl. Mater. 432 (2013) 94-101. doi:10.1016/j.jnucmat.2012.08.040.

[6] J.A. Simpson, J.K. Wright, L.J. Carroll, Novel Experiments to Characterize Creep-Fatigue Degradation in VHTR Alloys, Idaho Natl. Lab. (2013). http://www.osti.gov/scitech/biblio/1097150.

[7] L. Carroll, M. Carroll, Creep-Fatigue Behavior of Alloy 617 at 850 and $950^{\circ} \mathrm{C}$, Idaho Natl. Lab. INL/EXT-13 (2015).

[8] X. Chen, M.A. Sokolov, S. Sham, D.L. Erdman, J.T. Busby, K. Mo, et al., Experimental and modeling results of creep-fatigue life of Inconel 617 and Haynes 230 at $850^{\circ} \mathrm{C}, \mathrm{J}$. Nucl. Mater. 432 (2013) 94-101. doi:10.1016/j.jnucmat.2012.08.040.

[9] L.J. Carroll, C. Cabet, M.C. Carroll, R.N. Wright, The development of microstructural damage during high temperature creep-fatigue of a nickel alloy, Int. J. Fatigue. 47 (2013) 115-125. doi:10.1016/j.ijfatigue.2012.07.016.

[10] S.F. Di Martino, R.G. Faulkner, S.C. Hogg, S. Vujic, O. Tassa, Characterisation of microstructure and creep properties of alloy 617 for high-temperature applications, Mater. Sci. Eng. A. 619 (2014) 77-86. doi:10.1016/j.msea.2014.09.046. 
[11] H. Rao, K Bhanu Sankara, Meurer, H. -P, Schuster, Creep-Fatigue Interaction of Inconel 617 at $950^{\circ} \mathrm{C}$ in Simulated Nuclear Reactor Helium, Mater. Sci. Eng. A. 104 (1988) 3751.

[12] S.K. Sharma, G.D. Ko, F.X. Li, K.J. Kang, Oxidation and creep failure of alloy 617 foils at high temperature, J. Nucl. Mater. 378 (2008) 144-152. doi:10.1016/j.jnucmat.2008.04.021.

[13] T.C. Totemeier, H. Tian, Creep-fatigue-environment interactions in INCONEL 617, Mater. Sci. Eng. A. 468-470 (2007) 81-87. doi:10.1016/j.msea.2006.10.170.

[14] S. Schlegel, S. Hopkins, E. Young, J. Cole, T. Lillo, M. Frary, Precipitate Redistribution during Creep of Alloy 617, Metall. Mater. Trans. A. 40 (2009) 2812-2823. doi:10.1007/s11661-009-0027-7.

[15] F. Tahir, Y. Liu, Development of Creep-Dominant Creep-Fatigue Testing for Alloy 617, in: 57th AIAA/ASCE/AHS/ASC Struct. Struct. Dyn. Mater. Conf. San Diego, California, USA., AIAA SciTech, San Diego, 2016. doi:http://dx.doi.org/10.2514/6.2016-0668.

[16] E.P. Esztergar, Creep-fatigue Interaction and Cumulative Damage Evaluations for Type 304 Stainless Steel, Technical Report, Oak Ridge National Lab, Tennessee, 1972. http://www.iaea.org/inis/collection/NCLCollectionStore/_Public/04/038/4038440.pdf.

[17] J.K. Wright, Draft ASME Boiler and Pressure Vessel Code Section III, Division 5, Section HB, Subsection B, Code Case for Alloy 617 and Background Documentation, Idaho Natl. Lab. (2015).

[18] R.N. Wright, High Temperature Materials Characterization Database, Idaho National Lab.

[19] R. Campbell, Creep/fatigue interaction correlation for 304 stainless steel subjected to strain-controlled cycling with hold times at peak strain, J. Manuf. .... (1971). 
http://manufacturingscience.asmedigitalcollection.asme.org/article.aspx?articleid=144206 0.

[20] RCC-MRx, Design and Construction Rules for Mechanical Components of Nuclear installations, AFCEN. (2012).

[21] B. Fournier, M. Sauzay, C. Caës, M. Noblecourt, M. Mottot, a. Bougault, et al., Creepfatigue-oxidation interactions in a 9Cr-1Mo martensitic steel. Part I: Effect of tensile holding period on fatigue lifetime, Int. J. Fatigue. 30 (2008) 649-662. doi:10.1016/j.ijfatigue.2007.05.007.

[22] X.-L. Yan, X.-C. Zhang, S.-T. Tu, S.-L. Mannan, F.-Z. Xuan, Y.-C. Lin, Review of creepfatigue endurance and life prediction of 316 stainless steels, Int. J. Press. Vessel. Pip. 126127 (2015) 17-28. doi:10.1016/j.ijpvp.2014.12.002. 